\title{
Relação da Gravidade da Endoteliose Capilar Glomerular com Formas Clínicas das Doenças Hipertensivas na Gravidez
}

Autora: Adriana de Toledo Arruda Lippi

Orientador: Prof. Dr. Soubhi Kahhale

Dissertação de Mestrado apresentada à Faculdade de Medicina da Universidade de São Paulo em 21/10/99.

Estudou-se retrospectivamente o resultado do exame histopatológico do tecido renal obtido por biópsia percutânea de 285 pacientes que apresentaram hipertensão na gravidez de 1981 a 1996, na Clínica Obstétrica da FMUSP. Dentro dessa população selecionouse 120 casos cujos resultados mostraram endoteliose do capilar glomerular pura. Os cortes foram analisados pela microscopia óptica. A lesão endotelial é caracterizada por aumento do volume dos glomérulos com diminuição do diâmetro da luz do capilar, conseqüente à tumefação das células do endotélio e do mesângio. A intensidade da lesão foi classificada em graus: leve, moderada e grave. Do material analisado, 35\% foram de resultados compativeis com endoteliose leve, $54,2 \%$ moderada e 10,8\% graves. A gravidade dessa lesão associou-se de forma estatisticamente significativa com a gravidade clínica da doença hipertensiva específica da gravidez nas suas formas de pré-eclâmpsia leve (7), grave (54), eclâmpsia (20), e pré-eclâmpsia superajuntada a hipertensão arterial crônica (39). Não se observou associação entre a gravidade da endoteliose glomerular com a idade e a paridade das pacientes e nem tampouco com alguns exames laboratoriais tais como dosagem de ácido úrico, proteinúria e plaquetas. Também não se percebeu associação da lesão histológica com o exame de fundo de olho. Quando analisados alguns resultados referentes aos recémnascidos, também não se notou associação com os mesmos, exceto com índice de Apgar de 5 minuto.

Palavras-chave: Hipertensão. Pré-eclâmpsia. Anóxia perinatal. Hormonal

Autor: Jorge Nahás Neto

Orientador: Prof. Dr. Laurival A. De Luca

Dissertação apresentada ao Curso de Pós-Graduação em Ginecologia e Obstetrícia, área de concentração em Ginecologia da Faculdade de Medicina de Botucatu - UNESP, para obtenção do Título de Mestre em 17/11/99.

O objetivo deste estudo foi de analisar as alterações de densidade mamográfica, em mulheres na menopausa, submetidas a terapia de reposição hormonal (TRH). Estudou-se 96 pacientes, divididas em três grupos: G1, controle, de não-usuárias de TRH; G2, de usuárias de estrogênios conjugados $(0,625 \mathrm{mg} / \mathrm{dia})$ isolados ou associados a medroxiprogesterona $(2,5 \mathrm{mg} / \mathrm{dia}$ ou $5,0 \mathrm{mg} / 12$ dias); G3, usuárias de tibolona (2,5 mg/ dia). Critérios de inclusão: duas mamografias com intervalo minimo de 12 meses, sendo a primeira prévia a TRH. Avaliou-se a densidade mamográfica por dois métodos de classificação, o Wolfe (N1, P1, P2, DY) e o padronizado pelo Colégio Brasileiro de Radiologia (CBR $1,2,3,4)$. Os laudos foram revistos por dois radiologistas, separadamente. Verificou-se que as pacientes do grupo controle e usando tibolona eram mais velhas e com maior tempo de menopausa $(p<0,05)$. Sintomas mamários foram relatados por 9 pacientes sob TRH convencional e 4 sob tibolona, e em nenhuma do grupo controle $(p<0,05)$. Observou-se que mulheres com mamas pouco densas (N1 e P1 ou 1 e 2) tinham em média 3,6 gestações, diferentemente daquelas com mamas densas (P2 e DY ou 3 e 4), com 2,3 gestações ( $p<0,01$ ). Os achados mamográficos, iniciais e finais, foram confrontados entre os três grupos e não houve diferença significativa. Encontrou-se aumento de densidade mamográfica, segundo Wolfe, em $6,2 \%$ no controle, $9,4 \%$ sob TRH convencional e $3,2 \%$ sob tibolona e, segundo o $\mathrm{CBR}$, em $3,2 \%, 12,3 \%$ e $6,2 \%$, respectivamente. A concordância inter-observadores foi considerada boa, pelo método estatístico de kappa. Comparando-se Wolfe com o CBR, houve fraca concordância, atribuída ao fato das classes N1 e P1 de Wolfe serem englobadas na classe 1 do CBR. Este estudo sugere que a reposição hormonal não altera significativamente a densidade mamária. Entretanto, pequena porcentagem de mulheres mostraram aumento de tecido fibroglandular detectados pela mamografia. A tibolona parece provocar menos sintomas mamários e menores alterações de densidade mamária, quando comparada à TRH convencional.

Palavras-chave: Mamografia. Menopausa. Terapia de reposição hormonal. 